\title{
Surface Modification of Alumina Nanoparticles: A Dispersion Study in Organic Media
}

\author{
Esmaiel Soleimani* and Narges Zamani \\ Inorganic Chemistry Research Laboratory, Faculty of Chemistry, Shahrood University of Technology, Shahrood, IRAN \\ *Corresponding author: E-mail: essoleimani@ shshroodut.ac.ir; ssoleimani64@ gmail.com \\ Tel-fax: 982332395441
}

Received: 19-04-2017

\begin{abstract}
The alumina nanoparticles (NPs) have been synthesized from reaction between alum with ammonia and then calcined the precipitate at $1200{ }^{\circ} \mathrm{C}$ for $4 \mathrm{~h}$. Its surface was modified by oleic acid (OA) and trimethoxyvinylsilane (TMVS) in $o$-xylene at $50{ }^{\circ} \mathrm{C}$. The alumina NPs and its modified were characterized by XRD, FT-IR, SEM, EDX and TGA. The TGA analysis indicated that the grafting amount of OA and TMVS were 10.5 and $8.0 \%$ respectively. The dispersion of modified NPs was determined in monomers such as methyl methacrylate (MMA), butyl acrylate (BuA) and styrene (St) and in solvents such as ethanol, hexane and acetone. The experimental results showed that the highest dispersion was happened NPs modified by oleic acid in n-hexane, while the highest dispersion was observed NPs modified by TMVS in acetone. The results indicate that NPs modified by oleic acid formed a stable dispersion in MMA and BuA. The highest amount of dispersion happened NPs modified by oleic acid in MMA and BuA in initial weight of 5 and $2.5 \%$ respectively, while stable dispersion is formed in styrene when TMVS is used as modifier. The highest amount of dispersion was happened NPs modified by TMVS in styrene in initial weight of $2.5 \%$.
\end{abstract}

Keywords: Surface modification; alumina nanoparticles; oleic acid; trimethoxyvinylsilane; dispersibility; lipophilic degree

\section{Introduction}

In recent decades, the superfine particles in the nano-scale were of great interest due to their high surface area. ${ }^{1,2}$ Nano-sized ceramic powders, because of their excellent properties such as structural, optical and electrical behavior are effective in many fields..$^{3-5}$

Alumina is an important component of ceramic oxides. Alumina is used in the chemical industry, metallurgy, pharmaceutical and food industries due to the cheapness and having good mechanical and optical properties. ${ }^{6,7}$ $\mathrm{Al}_{2} \mathrm{O}_{3}$ has been widely used as catalyst and catalyst support, and also it has extensive applications in ceramic industry and structural composites. ${ }^{8}$

The Surface of mostly ceramic NPs such as alumina is polar and hydrophilic nature. That's why they do not disperse in organic environments. This feature prevents their use in the industry. This limitation can be overcome by modifying their surface by appropriate modifiers.

Fatty acids are used as modifiers for surface NPs, ${ }^{9-11}$ such as the surface of $\mathrm{SiO}_{2}$ NPs was modified by oleic acid. Oleic acid was connected through an ester bond to the surface of nano- $\mathrm{SiO}_{2}$. Results showed the modified NPs dispersion capabilities in non-polar solvents such as petroleum or mineral oils. ${ }^{12}$ The surface modified $\mathrm{ZnO}$ NPs increases dispersibility NPs in organic solvents and reduces photo-catalyst behavior. To do this, the surface of $\mathrm{ZnO}$ NPs was modified through using plasticizers silane $(\gamma$-methacryloxypropyltrimethoxysilan) and modified by polystyrene. Experimental results showed good dispersion of NPs in non-polar solvents such as acetone after surface modification. ${ }^{13}$ The surface $\mathrm{HfO}_{2} \mathrm{NPs}$ was modified by oleic acid. The presence of organic groups on the surface of the hafnium oxide NPs was proved by FT-IR spectra, and it indicated that oleic acid is attached to the carboxylate form on the surface of the $\mathrm{HfO}_{2}$ NPs. The surface of NPs changed from hydrophilic to hydrophobic by surface modification, so they were dispersed well in hexane. ${ }^{14}$

The nanocomposites (NCs) containing non-aggregated NPs were functionalized by two coupling agents (citric and ascorbic acids). Surface morphology indicated a picturesque network structure due to the existence of 
hydrogen bonds in the modified $\mathrm{Al}_{2} \mathrm{O}_{3}$. It also proved good dispersion of modified NPs in the polymer matrix..$^{15}$ The surface of alumina NPs was modified using epoxycontaining alkoxysilanes. Coupling of organic groups onto the surface of oxides using alkoxysilanes occurs via the formation of Si-O-M or metallasiloxane bonds. The surface modification decreased the thermal stability of alumina, in comparison with pristine alumina NPs. ${ }^{16}$

The surface of $\mathrm{Al}_{2} \mathrm{O}_{3}$ NPs was modified using vinyltrimethoxysilane (VTMS) layer. Analyses revealed that the silane coupling successfully adsorbed on the surface of nano $\mathrm{Al}_{2} \mathrm{O}_{3}$ via chemical interaction. Results show that NPs with $3 \%$ VTMS was in good agreement with the storage modulus and glass transition temperature values revealed by DMTA analysis. ${ }^{17}$

High performance polysulfone/alumina biocompatible NCs are reported and the effects of alumina surface modification are explored by Anaya and co-workers. ${ }^{18}$ They show that some fatty acids (palmitic, stearic, oleic and erucic acids) chemisorb over the surface of alumina forming nano-sized self-assembled structures. These structures present thermal transitions at high temperatures, $100{ }^{\circ} \mathrm{C}$ higher than the melting point of the pure acids, and are further shifted about $50{ }^{\circ} \mathrm{C}$ in the presence of polysulfone. $^{18}$

Llorente and co-workers have investigated the wear and mechanical behavior, along with the thermal stability, of polysulfone/modified alumina. Alumina NPs have been modified with polysulfone (PSU) chains of two different molecular weights. The modification leads to an enhanced homogeneous dispersion and enhanced mechanical and wear behavior. ${ }^{19}$ Nano-indentation measurements confirmed that the elastic modulus values were enhanced when modified NPs were used to prepare NCs. The PSU chains grafted to alumina promoted enhanced particle dispersion, which at the same time induced protection in the polysulfone matrix against wearing off. The results showed a clear tendency for increased strength and wear resistance, without sacrificing transparency. ${ }^{19}$

Alumina NPs have been modified with polysulfone (PSU) chains via 1,3-dipolar cyclo-addition reaction between functionalized alumina with vinyl groups and terminal azide polysulfone chains of two different molecular weights. ${ }^{20}$ Homo-polymer NCs have been prepared by extrusion and microinjection. The effectiveness of the grafts on the dispersibility has been analyzed in terms of the parameters that govern the wettability between grafted and matrix chains. The dispersion state and interfacial adhesion of PSU grafted NPs have been evaluated. Results show that the incorporation of the modified alumina improves the dispersion state in comparison with bare alumina NPs. These results can be explained by enthalpic compatibility between polysulfone grafted layer and host polysulfone matrix. ${ }^{20}$

The application of non-fouling thin films such as poly(ethylene glycol) (PEG) to alumina membranes is useful in drug delivery applications to prevent membrane fouling in long-term usage. Popat and co-workers have covalently attached PEG to nano-porous alumina surfaces to improve their non-fouling properties. ${ }^{21} \mathrm{~A}$ PEG-silane coupling technique was used to modify the surface.

The modification of nanometric aluminum oxides particles by bis-phosphonic acid-based oligomers of aromatic polyester, polyether, or polydimethylsiloxane (PDMS) was achieved with the formation of covalent bonds between the oxide and the oligomers. ${ }^{22}$ The melt blending of the unmodified as well as the modified particles with PMMA led to well-dispersed NCs structures. Thermal stability and fire behavior of PMMA were improved due to physical and physico-chemical processes involving the presence of the nanometric alumina. Significant improvements for these properties in relation to the grafting of the mineral were only noticed for the PDMS phosphonic acid-based formulation, despite the very low amount of oligomer present in PMMA. It is suggested that this compound could act in the condensed phase due to its important thermal stability and could also promote modifications of the degradation pathway of PMMA in the interphase region surrounding the alumina particles. ${ }^{22}$

Chemical surface modification of aluminum oxide (AO) NPs with graft copolymer of AO and poly (isobutyl vinyl ether) (PIBVE) (AO-graft-PIBVE) was carried out by ball milling of AO NPs with IBVE in vacuum at low temperature. The surface modified AO NPs with monodispersed particle diameter exhibited structural blue color which was evidenced by photograph, optical spectroscopy (UV-Vis) and SEM image. ${ }^{23}$

Several protocols reported for the surface modification of $\mathrm{Al}_{2} \mathrm{O}_{3} \mathrm{NPs}$, In this regard, different surfactants and organic compounds such as a silane coupling agent, isocyanate group, stearic acid, dimethyl sulfoxide, and acetic acid have been used as modifying agents. ${ }^{24-27}$ To the best of our knowledge, there is no report on the comparison of the effectiveness of different modifiers for $\mathrm{Al}_{2} \mathrm{O}_{3} \mathrm{NPs}$ and their compatibility in various organic solvents. In this study, the surface of alumina NPs was modified by two modifiers such as oleic acid (OA), trimethoxyvinylsilane (TMVS), as well as a mixture of two modified in three ratio (3:1), (1:1) and (1:3). Then the dispersibility of modified NPs was investigated in monomers such as methyl methacrylat (MMA), butyl acrylate (BuA) and styrene (St) and also in solvents including acetone, $\mathrm{n}$-hexane and ethanol with different levels of hydrophobicity.

\section{Experimental}

\section{1. Material and Methods}

In this work, the chemicals such as trimethoxyvinylsilane (TMVS), oleic acid (OA), ethanol, n-hexane, $o$ xylene, ammonia (25\%) and acetone were used as purchased by the chemical company (Merck) without any purifi- 
cation. Alum was prepared in our laboratory according to literature.

\section{2. Preparation of $\mathrm{Al}_{2} \mathrm{O}_{3} \mathrm{NPs}$}

The alumina NPs precursors were synthesized by the precipitation method and then calcination sediment. Firstly, $25 \mathrm{~mL}$ of $3.0 \mathrm{M}$ ammonia solution was dropped gradually and slowly into $25 \mathrm{~mL}$ of ammonium alum $\left[\left(\mathrm{NH}_{4} \mathrm{Al}(\mathrm{SO} 4)_{2} \cdot 12 \mathrm{H}_{2} \mathrm{O}\right] 1.0 \mathrm{M}\right.$ with vigorous stirring for 45 minutes. After a vigorous stirring for an hour, the reaction mixture was heated to $95^{\circ} \mathrm{C}$ and then kept at that temperature for $3 \mathrm{~h}$ for precipitation. The precipitate obtained was first washed three times with distilled water and then washed three times with anhydrous alcohol and then dried in an oven at $60^{\circ} \mathrm{C}$ for $10 \mathrm{~h}$. Finally, the dried precipitate was then calcined at $1200{ }^{\circ} \mathrm{C}$ for $4 \mathrm{~h}$ with a heating rate of $5{ }^{\circ} \mathrm{C} \mathrm{min}{ }^{-1}$. After cooling in the room temperature, the samples were milled and collected for characterization.

\section{3. Surface Modification of $\mathrm{Al}_{2} \mathrm{O}_{3} \mathrm{NPs}$}

The experimental method of surface modification of alumina NPs using both modifiers oleic acid (OA) and trimethoxyvinylsilanes (TMVS) is the same as follows:

$1.5 \mathrm{~g}$ of oleic acid (or TMVS) was dissolved in 50 $\mathrm{ml}$ of $o$-xylene and then $3.0 \mathrm{~g}$ of alumina NPs were added to it. The resulting suspension is heated at $50{ }^{\circ} \mathrm{C}$ within an hour along with magnetic stirring. The precipitate was centrifuged, and washed three times with $5 \mathrm{ml}$ toluene. Precipitate was dried in the oven at $60{ }^{\circ} \mathrm{C}$ for $24 \mathrm{~h}$.

\section{4. Effect of Modifiers Concentration}

Using the above method, various amount of oleic or TMVS $(0.025,0.05,0.15,0.25,0.35$ and $0.45,0.50 \mathrm{~g})$ were dissolved in $10 \mathrm{~mL} o$-xylene, and each solution was used in turn for modifying $1.0 \mathrm{~g}$ samples of $\mathrm{Al}_{2} \mathrm{O}_{3} \mathrm{NPs}$, and was stirred at $50{ }^{\circ} \mathrm{C}$ for an hour. The sediments were separated, washed three times with $5 \mathrm{~mL}$ toluene and dried in the oven at $60{ }^{\circ} \mathrm{C}$ for $24 \mathrm{~h}$. Lipophilicity of modified alumina NPs were carried out as below:

First $0.1 \mathrm{~g}$ of modified alumina NPs is added to 10 $\mathrm{mL}$ water. Then methanol is added drop wise through a burette to these dispersed NPs until no more sediment are formed. The volume of methanol is used to calculate the degree of lipophilicity of the surface of NPs.

\section{5. Measurement of Lipophilic Degree}

One way to measure the lipophilic degree (LD) of the surface of NPs is disperse a certain amount of modified NPs in water, and then to carry out titration with an organic solvent such as methanol. ${ }^{28}$

When unmodified alumina NPs is added to water, sedimentation takes place promptly, whereas the alumina
NPs modified by oleic acid (or TMVS) will dispersed in water. Drop wise addition of methanol from a burette to a solution of modified NPs $(0.1 \mathrm{~g}$ in $10 \mathrm{~mL}$ water $)$ causes the modified NPs to sediment gradually. The degree of lipophilicity can be calculated using Eq. (1) by knowing the volume of the methanol used:

$$
\mathrm{LD}=\frac{\mathrm{v}}{\mathrm{v}+10} \times 100
$$

In this equation, $\mathrm{V}$ is the volume of methanol $(\mathrm{mL})$ used. Measuring the degree of lipophilicity is used as a guide for surface modification.

\section{6. Dispersibitity Modified Alumina NPs}

$0.05 \mathrm{~g}$ of modified alumina NPs were dispersed in $10 \mathrm{~mL}$ of solvents such as n-hexane, ethanol and acetone, and was then ultrasound within $30 \mathrm{~min}$. Then, the samples were allowed to stand without shaking for $72 \mathrm{~h}$ in the lab, the particles were deposited. The precipitate then was centrifuged and dried in the oven at $60{ }^{\circ} \mathrm{C}$ for $24 \mathrm{~h}$. The amount of stable particles in dispersion was determined gravimetrically (\%). The initial weight percent of the modified alumina NPs varied from 2.5 to $30 \%$.

\section{7. Characterization of the Modified Alumina}

The X-ray diffraction patterns (XRD) of powder samples were recorded by XRD system BRUKER-XS for characterizing the crystalline structure of the NPs. The XRD diffractometer is operated at a voltage of $40 \mathrm{kV}$ and $\mathrm{Cu} \mathrm{K} \alpha$ radiation over Bragg angles ranging from 10 to $80^{\circ}$ with the scanning rate of $0.05^{\circ} \mathrm{C} \mathrm{min}^{-1}$. The surface morphology of samples was recorded using SEM, Hitachi Japan, and TESCAN model. The instrument was equipped with EDX analysis for the determination of elemental analysis. The EDX model and its detector type were S4800 (I) and 7747/17-ME, respectively. The FT-IR spectra of the samples were recorded on FT-IR Rayleigh WQF-510 a spectrophotometer. The spectra of solids were obtained using $\mathrm{KBr}$ pellets. Ultrasonic irradiation was carried out with an ultrasonic equipped with a probe which was immersed directly in the mixture solution system with frequency of $2.25 \times 104 \mathrm{~Hz}$ and power of $100 \mathrm{~W}$. Thermo-gravimetric analysis (TGA) was carried out on a TG-209 thermoanalyzer (Netzsch, Germany), oxygen atmosphere, heating rate $10{ }^{\circ} \mathrm{C} \mathrm{min}^{-1}$. An electric furnace of Raypa with HM-9 model was used for calcimining samples.

\section{Results and Discussion}

The $\mathrm{Al}_{2} \mathrm{O}_{3}$ NPs have been synthesized through chemical precipitation method from reaction between ammo- 
nium alum $\left[\mathrm{NH}_{4} \mathrm{Al}\left(\mathrm{SO}_{4}\right)_{2} \cdot 12 \mathrm{H}_{2} \mathrm{O}\right]$ with ammonia solution and then calcined the precipitate at $1200{ }^{\circ} \mathrm{C}$ for $4 \mathrm{~h}$. The reaction equations are as follows:

$$
\begin{aligned}
& \mathrm{NH}_{4} \mathrm{Al}\left(\mathrm{SO}_{4}\right)_{2} \cdot 12 \mathrm{H}_{2} \mathrm{O} \stackrel{\text { Dissolution in water }}{\longrightarrow} \\
& \mathrm{NH}_{4}^{+}{ }_{(\mathrm{aq})}+\mathrm{Al}^{3+}{ }_{(\mathrm{aq})}+2 \mathrm{SO}_{4}{ }^{2-}{ }_{(\mathrm{aq})}+12 \mathrm{H}_{2} \mathrm{O}_{(\mathrm{l})} \\
& \mathrm{NH}_{3(\mathrm{aq})}+\mathrm{H}_{2} \mathrm{O}_{(\mathrm{l})} \rightarrow \mathrm{NH}_{4}^{+}{ }_{(\mathrm{aq})}+\mathrm{OH}_{(\mathrm{aq})}^{-} \\
& \mathrm{Al}^{3+}{ }_{(\mathrm{aq})}+3 \mathrm{OH}_{(\mathrm{aq})}^{-} \rightarrow \mathrm{Al}(\mathrm{OH})_{3}(\mathrm{~s}) \\
& 2 \mathrm{Al}(\mathrm{OH})_{3(\mathrm{~s})} \stackrel{\text { calcined } 1200^{\circ} \mathrm{C}, 4 \mathrm{~h}}{\longrightarrow} \mathrm{Al}_{2} \mathrm{O}_{3}(\mathrm{~s})+ \\
& +3 \mathrm{H}_{2} \mathrm{O} \text { (g) }
\end{aligned}
$$

Preparation method of $\mathrm{Al}_{2} \mathrm{O}_{3}$ NPs is of unique advantages. Nanoparticles are obtained from inexpensive and easily available precursors, and without needing surfactants (surface active). The surface of alumina NPs was modified by two modifiers such as oleic acid (OA), trimethoxyvinylsilane (TMVS), as well as a mixture of two modified in three ratio (3:1), (1:1) and (1:3).

In order to confirm that the surface of alumina NPs is covered by the modifiers, the surface was studied by the usual methods of identification and morphology consideration.

\section{1. X-ray Diffraction Patterns}

The X-ray diffraction pattern of alumina NPs before and after modification by oleic acid and TMVS were recorded, and results are presented in Fig. 1. The eight characteristic angles viz $2 \theta$ equal to $18.8,20.5,32.9,36.9$, $39.4,45.6,61.2$ and $67.2^{\circ}$, which correspond well to the standard JCPDS card with number 29-1486, confirms that the crystal structure of $\mathrm{Al}_{2} \mathrm{O}_{3}$ is tetragonal. ${ }^{29,30}$ These peaks are corresponded to crystal planes of [111], [200], [220], [311], [222], [400], [511] and [440] respectively. Figs. 1b and 1c show that the characteristics of peaks after surface modification have not changed, and are the same as those of unmodified nano-alumina with tetragonal crystal structure. The average size of $\mathrm{Al}_{2} \mathrm{O}_{3}$ NPs modified by oleic acid and TMVS calculated from XRD diffraction pattern according to Debye-Scherer formula are 29.08 and $30.04 \mathrm{~nm}$ respectively.

\section{2. FT-IR Spectra}

In order to study the bonds formed, FT-IR spectra of NPs were recorded before and after surface modification by oleic acid and TMVS. These spectra are shown in Fig. 2. The observed band at $672 \mathrm{~cm}^{-1}$ in FT-IR of unmodified NPs (Fig. 2a) is due to stretching frequency of Al-O in
$\mathrm{Al}_{2} \mathrm{O}_{3}{ }^{31}$ The broad peaks at around 3442 and $1630 \mathrm{~cm}^{-1}$ are attributed to the stretching and bending bands of $\mathrm{O}-\mathrm{H}$ groups on the surface of alumina, respectively. ${ }^{32,33}$

In the FT-IR spectra of nano-alumina modified with oleic acid (OA) and trimethoxy-vinylsilane (TMVS) in Figs. $2 \mathbf{b}$ and $\mathbf{2 c}$, in addition to the absorption bands of vibration frequencies $\mathrm{Al}-\mathrm{O}$ and $-\mathrm{OH}$ groups, new bands were observed. Two absorption bands at 2854 and $2924 \mathrm{~cm}^{-1}$ (Fig. 2b) are due to the vibrational frequencies of $\mathrm{CH}_{2}$ and $\mathrm{CH}_{3}$ groups of oleic acid covering the surface of nanoparticles. ${ }^{34}$ An absorption band at $1625 \mathrm{~cm}^{-1}$ (Fig. 2c) is related to the presence of vinyl double bonds $(\mathrm{C}=\mathrm{C})$ of trimethoxyvinylsilane coated on the surface of alumina NPs. ${ }^{35}$ The observed band at $1016 \mathrm{~cm}^{-1}$ is due to the stretching frequency of Si-O in silane. ${ }^{36}$ These observations in FT-IR spectra confirm that the surface of $\mathrm{Al}_{2} \mathrm{O}_{3} \mathrm{NPs}$ is modified by oleic acid and TMVS.

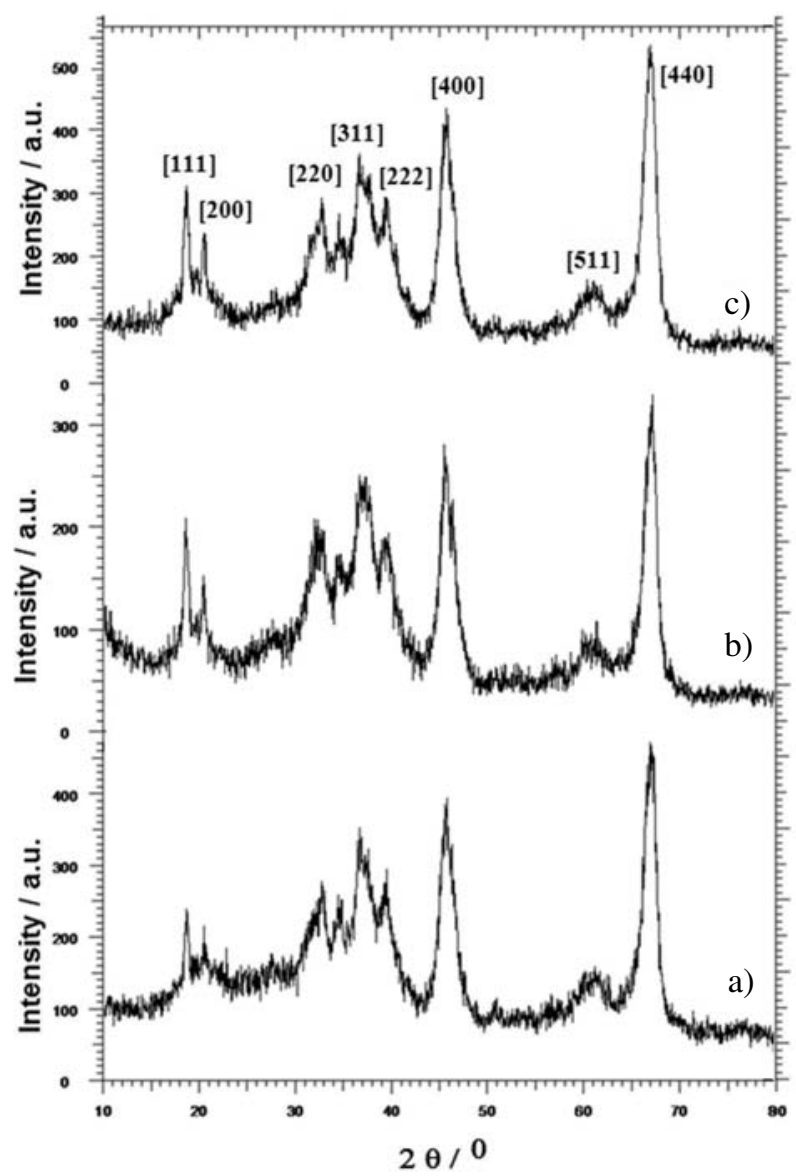

Fig. 1: XRD diffraction patterns of: (a) $\mathrm{Al}_{2} \mathrm{O}_{3} \mathrm{NPs}$; (b) $\mathrm{Al}_{2} \mathrm{O}_{3} \mathrm{NPs}$ modified by oleic acid; (c) $\mathrm{Al}_{2} \mathrm{O}_{3}$ NPs modified by TMVS.

\section{3. SEM Images \& EDX Analysis}

Nanoparticles have a tendency to aggregate because of high surface energy. Therefore, surface modification is expected to decrease aggregation and improve dispersibi- 


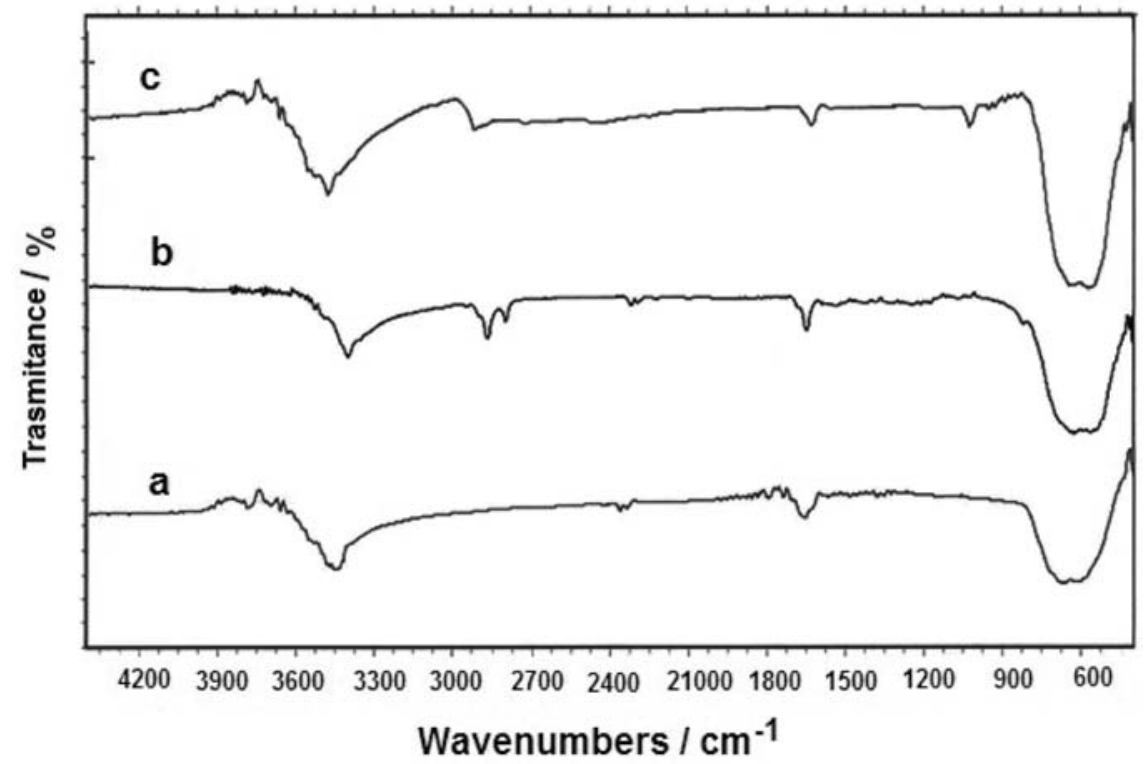

Fig. 2: FT-IR spectra of: (a) bare $\mathrm{Al}_{2} \mathrm{O}_{3} \mathrm{NPs} ;\left(\mathrm{b} \mathrm{Al}_{2} \mathrm{O}_{3}\right.$ NPs modified by oleic acid; (c $\mathrm{Al}_{2} \mathrm{O}_{3}$ NPs modified by TMVS.
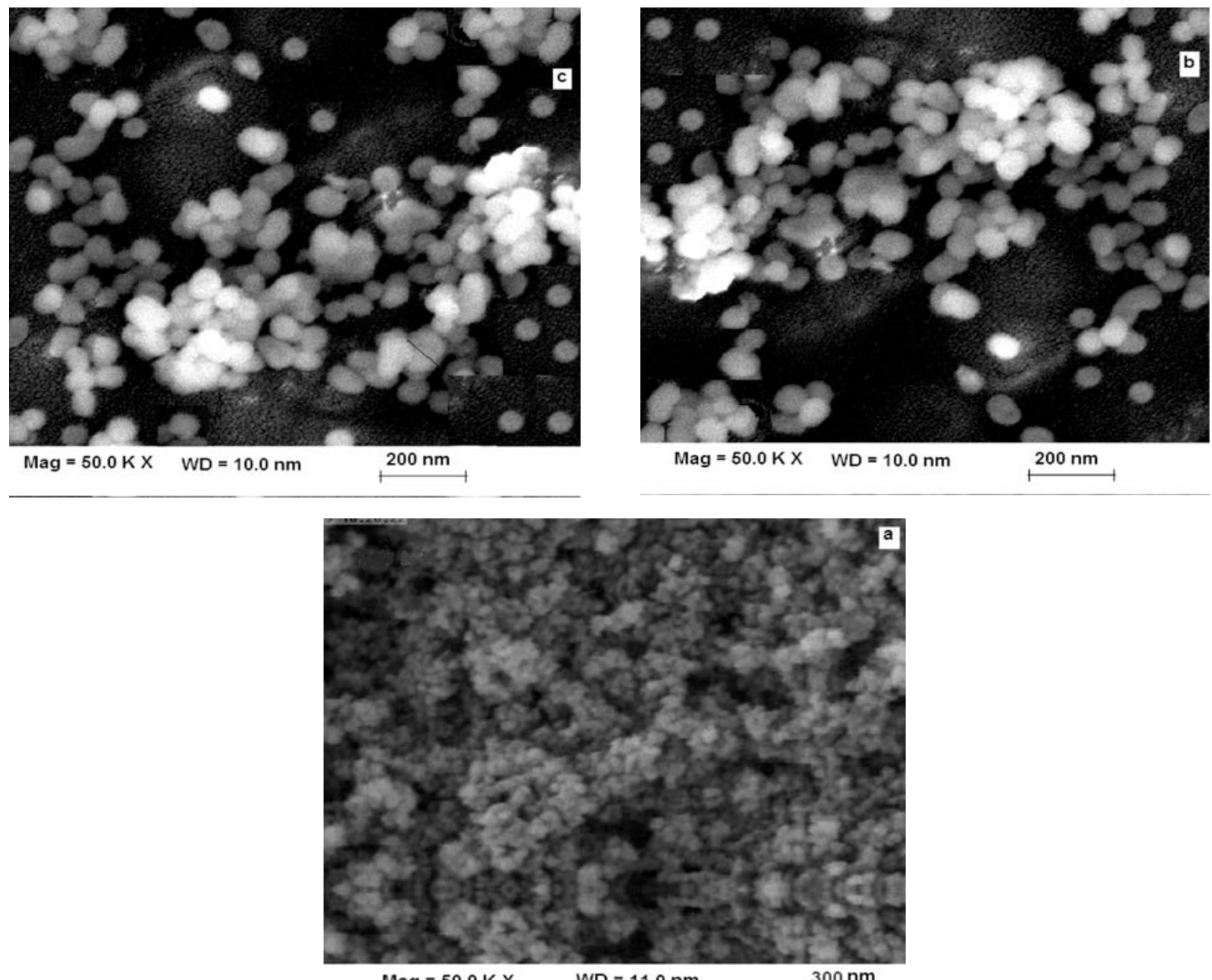

Mag $=50.0 \mathrm{KX}$

$W D=11.0 \mathrm{~nm}$

$300 \mathrm{~nm}$

Fig. 3: SEM images of: (a) $\mathrm{Al}_{2} \mathrm{O}_{3} \mathrm{NPs}$; $\left(\mathrm{b} \mathrm{Al}_{2} \mathrm{O}_{3}\right.$ NPs modified by oleic acid; (c $\mathrm{Al}_{2} \mathrm{O}_{3}$ NPs modified by TMVS. 

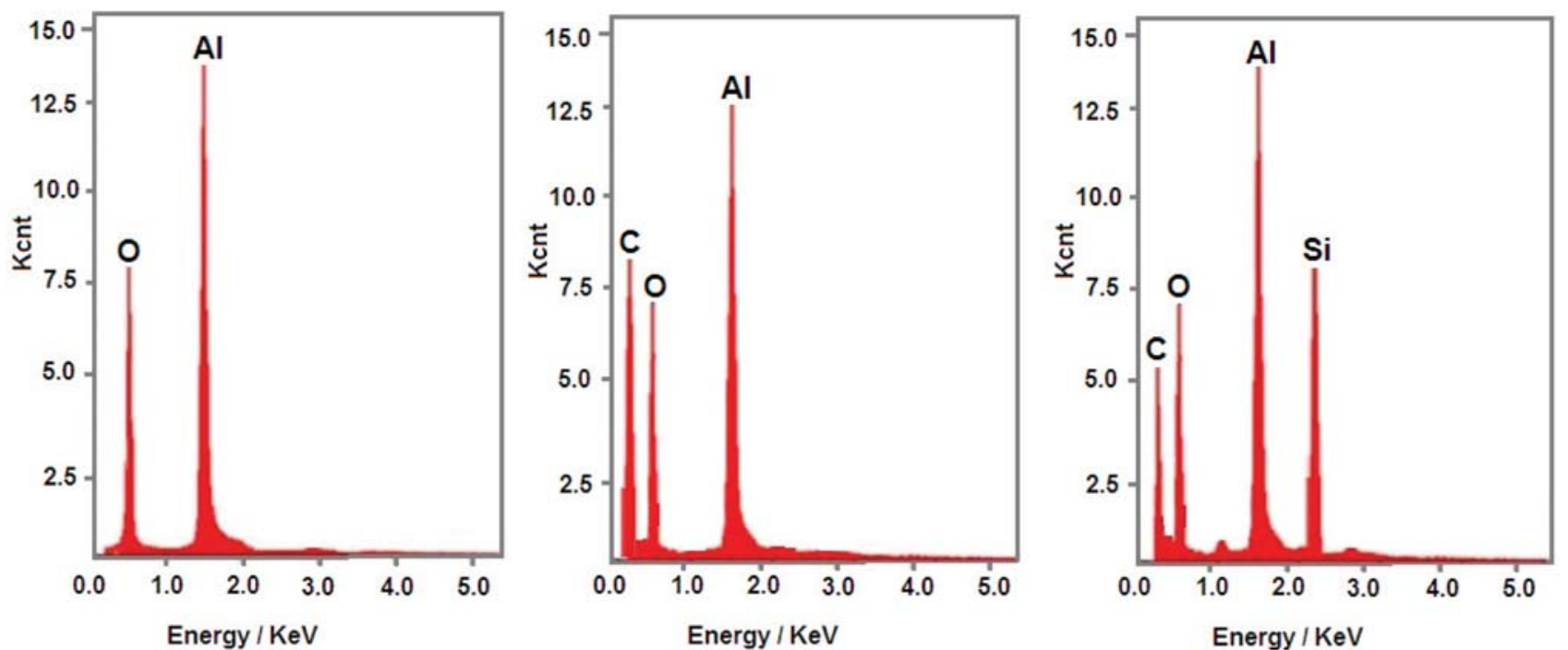

Fig. 4: EDX spectra of: (a) $\mathrm{Al}_{2} \mathrm{O}_{3} \mathrm{NPs}$; (b) $\mathrm{Al}_{2} \mathrm{O}_{3}$ NPs modified by oleic acid; (c $\mathrm{Al}_{2} \mathrm{O}_{3}$ NPs modified by TMVS.

lity. ${ }^{37-39}$ Thus, to studying dispersibility, SEM images of alumina nanoparticles before and after modification by oleic acid and TMVS have been recorded which are shown in Fig. 3. As it can be seen in Fig. 3a, alumina unmodified NPs are highly aggregated which is due to large surface area to volume ratio and high energy of the surface of nanoparticles. Whereas in Figs. 3b and $\mathbf{3 c}$ good dispersibility can be seen which are due to modification of NPs by oleic acid and TMVS respectively? This improvement in dispersibility of NPs certainly confirms the surface modification of NPs by oleic acid and TMVS. The size of the modified alumina NPs appeared to be higher (50 $\mathrm{nm}$ ) in comparison to bare alumina NPs from the XRD results $(30 \mathrm{~nm})$.

The EDX spectra of $\mathrm{Al}_{2} \mathrm{O}_{3}$ NPs and its modified by oleic acid and TMVS are shown in Fig. 4. The EDX spectrum given in Fig. 4a shows the presence of $\mathrm{Al}$ and $\mathrm{O}$ as the only elementary components of $\mathrm{Al}_{2} \mathrm{O}_{3}$ NPs. The presence of carbon and oxygen in alumina NPs modified by oleic acid (Fig. 4b), and presence of carbon, oxygen and silicon in alumina NPs modified by TMVS (Fig. 4c) are the proof for surface modification of $\mathrm{Al}_{2} \mathrm{O}_{3}$ NPs respectively, and which were absent in bare alumina NPs.

\section{4. TGA Analysis}

TGA analysis is taken to prove that how many of modifier is grafted on the surface of nanoparticles. TGA curves alumina NPs and its modified by oleic acid and TMVS are given in Fig. 5. The alumina NPs modified by oleic acid has a total weight loss of $10.5 \%$, when the temperature changes from 255 to $560{ }^{\circ} \mathrm{C}$, which is due to the burning of oleic acid on the surface of modified alumina NPs (Fig. 5b). The similar behavior was observed in alumina NPs modified by TMVS, with a total weight loss of $8 \%$, when the temperature changes from 248 to $475{ }^{\circ} \mathrm{C}$, which may be attributed the burning of silane compound on surface of modified alumina NPs (Fig. 5c).

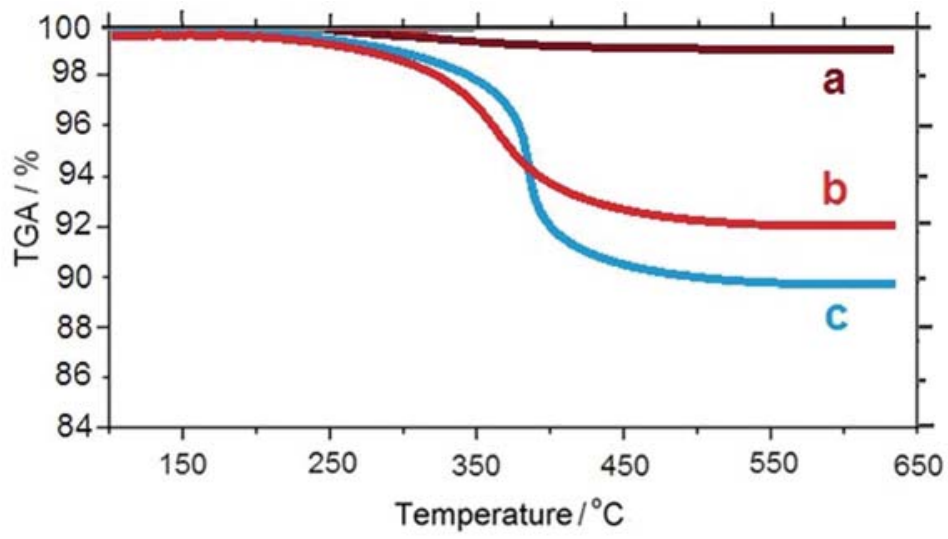

Fig. 5: TGA thermo-gram of: (a) un-modified alumina NPs; (b) alumina NPs modified by TMVS; (c) alumina NPs modified by oleic acid. 


\section{5. The amount of Surface Modifier}

Different amount of oleic acid and TMVS (2.5, 5.0, 7.5, 10.0, 12.5, 15.0 and 20\%) as surface modifier were applied on alumina NPs, and the lipophilic degree (LD) of the modified NPs was measured. The results obtained are presented in Table $\mathbf{1}$ as the variation of lipophilic degree versus amount of modifier. It can be seen from data that lipophilicity increases with the rise of amount of modifier up to $12.5 \%$ for oleic acid, and $10.0 \%$ for TMVS. However, if the amount of modifier is increased above this amount the lipophilicity starts to decrease. It may be due to enlarging of chain hydrocarbon of the modifier which can stop the carboxylic group $(-\mathrm{COOH})$ of oleic acid or methoxy moiety $\left(-\mathrm{OCH}_{3}\right)$ of TMVS to react with the hydroxyl group on the surface of alumina NPs. ${ }^{14}$

\section{6. Dispersibility of the Modified Alumina NPs}

Knowing that the incorporation of NPs into polymers can leads to improved mechanical behavior and thermal stability of polymers. Uniform and stable dispersion of NPs in the monomer is an important factor in the preparation of polymeric NCs. Therefore, effect of type and amount of modifiers were investigated on the dispersion of NPs in the monomers such as methylmethacrylate (MMA), butylacrylat (BuA) and styrene (St). To do this, certain amount of modified alumina NPs was dispersed in each monomer under stirring for one hour at room temperature. The percent of the initial weight of the modified alumina NPs varied from 2.5 to $30 \%$. Then, modified alumina NPs loaded monomers were allowed to stand at room temperature for $72 \mathrm{~h}$. The precipitated part of the NPs was separated and the amount of the stable particles in dispersion was determined gravimetrically. The results are shown in Table 2.

As it can be seen in the above table, the results indicate that the majority of modified $\mathrm{Al}_{2} \mathrm{O}_{3} \mathrm{NPs}$ by oleic acid (OA) precipitate in styrene; While $\mathrm{OA}-\mathrm{Al}_{2} \mathrm{O}_{3} \mathrm{NPs}$ formed a stable dispersion in MMA and BuA monomers. The highest amount of dispersion of $\mathrm{OA}-\mathrm{Al}_{2} \mathrm{O}_{3} \mathrm{NPs}$ in methyl methacrylate monomer happened in initial weight of 5 and $10 \%$. Similarly, the highest amount of dispersibility of OA- $\mathrm{Al}_{2} \mathrm{O}_{3} \mathrm{NPs}$ in butyl acrylate monomer occurred in initial weight of 2.5 and $10 \%$. The results also represent that when TMVS is used as modifier, TMVS- $\mathrm{Al}_{2} \mathrm{O}_{3} \mathrm{NPs}$ are stable in Styrene, however they were settled down in MMA and BuA monomers. The highest amount of dispersion of TMVS- $\mathrm{Al}_{2} \mathrm{O}_{3}$ NPs in styrene monomer happened in initial weight of $2.5,10$ and $5 \%$.

Moreover, when a mixture of modifiers was used and the ratio of oleic acid to trimethoxyvinylsilane (OA: TMVS) was varied from 3:1 to $1: 3$ dispersibility behavior of modified $\mathrm{Al}_{2} \mathrm{O}_{3} \mathrm{NPs}$ was changed, solid content of final stable dispersions are shown in Table 3. The amount of dispersibility of NPs was increased in all three monomers when the amount of oleic acid was high in the mixture modifiers (OA: TMVS, 3:1). On the other hand, the amount of dispersibility of alumina NPs increased in styrene monomer in all three cases including: the mixture of oleic acid (OA) and trimethylvinylsilane (TMVS) modifiers $(3: 1,1: 1$ and $1: 3)$.

These findings illustrated that the surface modification of $\mathrm{Al}_{2} \mathrm{O}_{3} \mathrm{NPs}$ with oleic acid, trimethoxyvinylsilane and mixture of modifiers OA-TMVS would increase the compatibility between NPs with MMA and styrene, respectively. Either this contributes to a better dispersibility of NPs in MMA or Styrene. One can justify this fact by comparing the polarity of monomer and relevant modifier.

Table 1: The LD of alumina NPs modified by oleic acid (OA) and TMVS (\%) in different amount of modifiers.

\begin{tabular}{|c|c|c|c|c|c|c|c|}
\hline Amount of modifiers (\%) & 2.5 & 5.0 & 7.5 & 10.0 & 12.5 & 15.0 & 20.0 \\
\hline LD NPs modified by OA (\%) & 15.22 & 15.85 & 18.47 & 22.15 & 24.71 & 18.95 & 14.27 \\
\hline LD NPs modified by TMVS (\%) & 11.11 & 16.13 & 18.75 & 23.45 & 18.25 & 14.75 & 13.07 \\
\hline
\end{tabular}

Reaction conditions: Amount of alumina NPs $1.0 \mathrm{~g}$, o-xylene as solvent $10 \mathrm{~mL}$, temperature $50{ }^{\circ} \mathrm{C}$ and reaction time $1 \mathrm{~h}$.

Table 2: Dispersion of alumina NPs modified with oleic acid (OA) and trimethoxy-vinylsilan (TMVS) in some organic media (\%).

\begin{tabular}{|c|c|c|c|c|c|c|}
\hline \multirow{2}{*}{$\begin{array}{l}\text { Initial weight percent } \\
\text { percent alumina NPs }(\%)\end{array}$} & \multicolumn{2}{|c|}{ Dispersion in MMA } & \multicolumn{2}{|c|}{ Dispersion in BuA } & \multicolumn{2}{|c|}{ Dispersion in St } \\
\hline & $\mathbf{O A}$ & TMVS & OA & TMVS & $\mathbf{O A}$ & TMVS \\
\hline 2.5 & 2.12 & 1.73 & 1.93 & 1.54 & 1.52 & 2.04 \\
\hline 5 & 4.15 & 3.64 & 3.47 & 2.74 & 3.12 & 3.75 \\
\hline 10 & 8.24 & 6.14 & 7.54 & 6.85 & 6.44 & 7.88 \\
\hline 15 & 12.04 & 9.45 & 10.51 & 9.22 & 9.12 & 10.49 \\
\hline 20 & 15.25 & 11.42 & 14.12 & 11.95 & 11.27 & 14.17 \\
\hline 25 & 18.63 & 13.94 & 15.84 & 14.01 & 13.94 & 17.81 \\
\hline 30 & 22.74 & 17.22 & 20.46 & 16.04 & 17.01 & 21.48 \\
\hline
\end{tabular}


Table 3: Dispersion of alumina NPs modified with different ratios of mixtures of OA: TMVS (3:1, 1:1 and1:3) in some organic media (\%).

\begin{tabular}{lccccccrrr}
\hline $\begin{array}{l}\text { Initial weight } \\
\text { percent alumina }\end{array}$ & \multicolumn{3}{c}{$\begin{array}{c}\text { Dispersion in MMA (\%) } \\
\text { (OA:TMVS) }\end{array}$} & \multicolumn{3}{c}{$\begin{array}{c}\text { Dispersion in BuA (\%) } \\
\text { (OA:TMVS) }\end{array}$} & \multicolumn{3}{c}{$\begin{array}{c}\text { Dispersion in St (\%) } \\
\text { (OA:TMVS) }\end{array}$} \\
NPs (\%) & $\mathbf{( 3 : 1 )}$ & $\mathbf{( 1 : 1 )}$ & $\mathbf{( 1 : 3 )}$ & $\mathbf{( 3 : 1 )}$ & $\mathbf{( 1 : 1 )}$ & $\mathbf{( 1 : 3 )}$ & $\mathbf{( 3 : 1 )}$ & $(\mathbf{1 : 1 )}$ & $\mathbf{( 1 : 3 )}$ \\
\hline 2.5 & 1.11 & 0.98 & 0.75 & 1.35 & 1.12 & 0.95 & 2.25 & 1.87 & 1.32 \\
5 & 2.15 & 1.75 & 1.25 & 2.78 & 2.05 & 1.84 & 3.87 & 3.42 & 3.11 \\
10 & 6.04 & 5.24 & 3.73 & 7.13 & 5.88 & 5.28 & 8.09 & 7.04 & 6.45 \\
15 & 13.21 & 9.08 & 8.22 & 13.56 & 9.86 & 8.94 & 13.91 & 10.23 & 10.04 \\
20 & 14.75 & 13.15 & 12.28 & 15.25 & 14.55 & 13.09 & 17.44 & 15.85 & 14.93 \\
25 & 17.73 & 17.22 & 15.63 & 18.84 & 16.34 & 14.83 & 20.03 & 18.44 & 17.05 \\
30 & 20.34 & 18.35 & 15.11 & 22.47 & 19.74 & 17.56 & 24.79 & 21.58 & 21.17 \\
\hline
\end{tabular}

Table 4: Dispersion of alumina NPs modified with oleic acid (OA) and trimethoxy-vinylsilan (TMVS) in some organic solvents (\%).

\begin{tabular}{ccccccc}
\hline $\begin{array}{l}\text { Initial weight percent } \\
\text { alumina NPs (\%) }\end{array}$ & \multicolumn{2}{c}{ Dispersion in n-hexane (\%) } & \multicolumn{2}{c}{ Dispersion in acetone (\%) } & $\begin{array}{c}\text { Dispersion in ethanol (\%) } \\
\text { OA }\end{array}$ & TMVS \\
\hline 2.5 & 2.01 & 1.62 & 1.71 & 1.95 & 1.25 & 1.41 \\
5 & 4.12 & 3.25 & 3.15 & 3.85 & 2.12 & 1.94 \\
10 & 7.24 & 4.93 & 5.45 & 6.04 & 3.74 & 4.15 \\
15 & 10.46 & 6.16 & 7.37 & 8.82 & 4.92 & 4.31 \\
20 & 13.48 & 10.72 & 11.29 & 11.25 & 7.15 & 7.08 \\
25 & 15.94 & 11.07 & 12.83 & 13.91 & 9.29 & 9.48 \\
30 & 20.42 & 13.97 & 14.12 & 17.42 & 10.87 & 9.95 \\
\hline
\end{tabular}

The dispersion percentage of the modified alumina NPs by oleic acid and TMVS also were investigated in solvents such as n-hexane, acetone and ethanol and the results are shown in Table 4. The highest dispersion of alumina NPs modified with oleic acid happened in n-hexane and the lowest occurred in ethanol. While the highest dispersion of alumina NPs modified by TMVS can be seen in acetone and lowest dispersion occur in ethanol.

The dispersibility of the alumina NPs modified by oleic acid (OA) and trimethoxyvinylsilane (TMVS) in monomers of styrene (St), poly(methyl methacrylate) (PMMA) and butylacrylate (BuA) was compared with the previous work of modified $\mathrm{ZnO}$ NPs and the results are shown in Table 5.

As it can be seen in Table 5, the results indicate that the majority of modified $\mathrm{Al}_{2} \mathrm{O}_{3}$ NPs by oleic acid precipitate in styrene and formed a stable dispersion in MMA and BuA monomers. While contrary to this behavior was observed in $\mathrm{ZnO}$ NPs modified by oleic acid. ${ }^{40}$ The majority of modified $\mathrm{Al}_{2} \mathrm{O}_{3}$ NPs by TMVS precipitate in MMA and
$\mathrm{BuA}$ monomers and formed a stable dispersion in styrene. While the majority of modified $\mathrm{ZnO}$ NPs by TMVS precipitate in styrene and $\mathrm{BuA}$ monomers and formed a stable dispersion in MMA monomer. ${ }^{40}$ On the other hand, the stability time of dispersion of modified nanoparticles in our work $(72 \mathrm{~h})$ is longer than the previous work $(24 \mathrm{~h}){ }^{40}$

\section{Conclusions}

The alumina NPs have been synthesized from reaction between ammonium alum with ammonia solution and then calcined the precipitate at $1200{ }^{\circ} \mathrm{C}$. The surface of alumina NPs was changed to the hydrophobic nature due to surface modified by oleic acid (OA) and trimethoxyvinylsilane (TMVS). TGA analysis for alumina NPs indicates that the grafting amount of oleic acid and TMVS are 10.5 and $8 \%$ respectively. The presence of organic groups on the surface of NPs was proved by FT-IR spectra, and shown that oleic acid is attached to the carboxylate form

Table 5: Stable time and dispersion of modified nanoparticles.

\begin{tabular}{lcccc}
\hline & $\begin{array}{c}\text { Stable } \\
\text { time/ }\end{array}$ & $\begin{array}{c}\text { Stable } \\
\text { dispersion }\end{array}$ & $\begin{array}{c}\text { Majority } \\
\text { precipitation }\end{array}$ & References \\
\hline $\mathrm{Al}$ 2O3-OA & 72 & $\mathrm{MMA}, \mathrm{BuA}$ & $\mathrm{St}$ & This work \\
$\mathrm{A} 12 \mathrm{O} 3-\mathrm{TMVS}$ & 72 & $\mathrm{St}$ & $\mathrm{MMA}, \mathrm{BuA}$ & This work \\
$\mathrm{ZnO-OA}$ & 24 & $\mathrm{St}$ & $\mathrm{MMA}, \mathrm{BuA}$ & 40 \\
$\mathrm{ZnO}-\mathrm{TMVS}$ & 24 & $\mathrm{MMA}$ & $\mathrm{St}, \mathrm{BuA}$ & 40 \\
\hline
\end{tabular}


and TMVS connected via the formation of Si-O-M bond on the surface of alumina NPs. The change of behavior of hydrophobic surfaces of modified alumina NPs was confirmed through lipophilic degree (LD) experiments. The results obtained are presented that lipophilic degree increased with the rise of amount of modifier up to $12.5 \%$ for oleic acid, and $10.0 \%$ for TMVS. Experimental results showed that the highest dispersion was happened alumina NPs modified by oleic acid in n-hexane and the lowest in ethanol, while the highest dispersion was observed alumina NPs modified by TMVS in acetone and lowest dispersion in ethanol. The results indicate that modified $\mathrm{Al}_{2} \mathrm{O}_{3}$ NPs by oleic acid (OA) formed a stable dispersion in MMA and BuA monomers. The highest amount of dispersion was happened $\mathrm{OA}-\mathrm{Al}_{2} \mathrm{O}_{3} \mathrm{NPs}$ in MMA and BuA monomers in initial weight of 5 and $2.5 \%$ respectively, while stable dispersion are formed in styrene when TMVS is used as modifier. The highest amount of dispersion was happened TMVS- $\mathrm{Al}_{2} \mathrm{O}_{3}$ NPs in styrene monomer in initial weight of $2.5 \%$.

\section{Acknowledgements}

The authors would like to appreciate the Research Council of Shahrood University of Technology for supporting this project financially.

\section{References}

1. Y. Xia, P. Yang, Y. Sun, Y. Wu, B. Mayers, B. Gates, Y. Yin, F. Kim, H. Yan, Adv. Mater. 2003, 15, 353-389. https://doi.org/10.1002/adma.200390087

2. N. A. M. Barakat, K. A. Khalil, I. H. Mahmoud, M. A. Kanjwal, F. A. Sheikh, H. Y. Kim, J. Phys. Chem. C 2010, 114, 15589-15593. https://doi.org/10.1021/jp1041074

3. D. Gal, G. Hodes, D. Lincot, H. W. Schock, Thin Solid Films 2000, 361-362, 79-83. https://doi.org/10.1016/S0040-6090(99)00772-5

4. K. Hara, T. Horiguchi, T. Kinoshita, K. Sayama, H. Sugihara, H. Arakawa, Sol. Energy Mater. Sol. Cells 2000, 64, 115134. https://doi.org/10.1016/S0927-0248(00)00065-9

5. T. Pauporte, D. Lincot, Electrochim. Acta 2000, 45 33453353. https://doi.org/10.1016/S0013-4686(00)00405-9

6. S. Guobin, Z. Huaiying, C. Weiquan, X. Jianmin, L. Huizhou, Biophys. J. 2005, 89, L58-L60. https://doi.org/10.1529/biophysj.105.073718

7. S. Chibowski, M. Paszkiewicz, M. Krupa, Powder Technol. 2000, 107, 251-225.

https://doi.org/10.1016/S0032-5910(99)00194-1

8. H. Y. Zhang, G. B. Shan, H. Z. Liu, J. M. Xing, Surf. Coat. Tech. 2007, 201, 6917-6921. https://doi.org/10.1016/j.surfcoat.2006.11.043

9. C. Wang, Y. Sheng, H. Bala, X. Zhao, J. Zhao, X. Ma, Z. Wang, Mater. Sci. Eng. C 2007, 27, 42-45. https://doi.org/10.1016/j.msec.2006.01.003

10. C. Wang, X. Zhao, J. Zhao, Y. Liu, Y. Sheng, Z. Wang, Appl. Surf. Sci. 2007, 253, 4768-4772. https://doi.org/10.1016/j.apsusc.2006.10.048

11. X. Ma, Y. Liu, Y. Yu, H. Lei, X. Lv, L. Zhao, S. Ren, Z. Wang, J. Appl. Polym. Sci. 2008, 108, 1421-1425. https://doi.org/10.1002/app.27812

12. Z. Li, Y. Zhu, Appl. Surf. Sci. 2003, 211, 315-320. https://doi.org/10.1016/S0169-4332(03)00259-9

13. R. Y. Hong, J. H. Li, L. L. Chen, D. Q. Liu, H. Z. Li, Y. Zheng, J. Ding, Powder Technol. 2009, 189, 426-432. https://doi.org/10.1016/j.powtec.2008.07.004

14. R. Ramos-González, L. A. García-Cerda, M. A. QuevedoLópez, Appl. Surf. Sci. 2012, 258, 6034-6039. https://doi.org/10.1016/j.apsusc.2012.02.122

15. S. Mallakpour, R. Sadeghzadeh, Adv. Polym. Technol., doi:10.1002/adv. 21622

16. L. A. S. A. Prado, M. Sriyai, M. Ghislandi, A. Barros-Timmons, K. Schulte, J. Braz. Chem. Soc. 2010, 21, 2238-2245. https://doi.org/10.1590/S0103-50532010001200010

17. M. Rostam, J. Nanomed. Nanotechnol. 2016, 7, 365.

18. S. Anaya, B. Serrano, B. Herrero, A. Cervera, J. Baselga, ACS Appl. Mater. Interfaces 2014, 6, 14460-14468. https://doi.org/10.1021/am503744z

19. A. Llorente, B. Serrano, J. Baselga, G. Gedler, R. Ozisik, RSC Adv. 2016, 6, 100239-100247.

20. A. Llorente, B. Serrano, J. Baselga, Macromolecular Research 2017, 25, 11-20. https://doi.org/10.1007/s13233-016-4150-1

21. K. C. Popat, G. Mor, C. A. Grimes, T. A. Desai, Langmuir 2004, 20, 8035-8041. https://doi.org/10.1021/la049075x

22. N. Cinausero, N. Azema, M. Cochez, M. Ferriol, M. Essahli, F. Ganachaud, J.-M. Lopez-Cuesta, Polym. Adv. Technol. 2008, 19, 701-709. https://doi.org/10.1002/pat.1157

23. T. Motokawa, M. Makino, K. Yamamoto, H. Takase, S. Nagano, Y. Enomoto-Rogers, T. Iwata, T. Kawaguchi, M. Sakaguchi, Adv. Powder Technol. 2017, 28, 266-279. https://doi.org/10.1016/j.apt.2016.09.031

24. S. Mallakpour, E. Khadem, J. Mol. Struct. 2014, 1075, 196203. https://doi.org/10.1016/j.molstruc.2014.06.081

25. S. Mallakpour, P. Sirous, Polym. Plast. Technol. Eng. 2015, 54, 532-540. https://doi.org/10.1080/03602559.2014.961083

26. S. Mallakpour, E. Khadem, Synth. React. Inorg. Met.-Org. Nano-Met. Chem. 2015, 45, 1773-1779. https://doi.org/10.1080/15533174.2013.872130

27. Y. P. Zheng, J. X. Zhang, Q. Li, W. Chen, X. Zhang, Polym. Plast. Technol. Eng. 2009, 48, 384-388. https://doi.org/10.1080/03602550902725381

28. R. Y. Hong, L. L. Chen, J. H. Li, H. Z. Li, Y. Zheng, J. Ding, Polym. Adv. Technol. 2007, 18, 901-909. https://doi.org/10.1002/pat.926

29. Z. Ghezelbash, D. Ashouri, S. Mousavian, A. M. Ghandi, Y. Rahnama, Bull. Mater. Sci. 2012, 35, 925-931. https://doi.org/10.1007/s12034-012-0385-4 
30. R. Y. Hong, J. Z. Qian, J. X. Cao, Powder Technol. 2006, $163,160-168$. https://doi.org/10.1016/j.powtec.2006.01.015

31. Y. Sui, Y. Cui, Y. Nie, G. M. Xia, G. X. Sun, J. T. Han, Colloids Surfaces B 2012, 93, 24-28. https://doi.org/10.1016/j.colsurfb.2011.11.054

32. Y. Wang, W. Eli, L. Zhang, H. Gao, Y. Liu, P. Li, Adv. Powder Technol. 2010, 21, 203-205. https://doi.org/10.1016/j.apt.2009.12.006

33. T. F. Gan, B. Q. Shentu, Z. X. Weng, Chin. J. Polym. Sci. 2008, 26, 489-494. https://doi.org/10.1142/S0256767908003163

34. J. Zhao, M. Milanova, M. M. C. G. Warmoeskerken, V. Dutschk, Colloids Surfaces A 2012, 413, 273-279. https://doi.org/10.1016/j.colsurfa.2011.11.033

35. M.-E. Becerra, N.-P. Arias, O.-H. Giraldo, F.-E. López-
Suárez, M.-J. Illán-Gómez, A. Bueno-López, Catalysts 2012, 2, 352-367. https://doi.org/10.3390/catal2030352

36. F. Klose, T. Wolff, H. Lorenz, A. Seidel-Morgenstern, Y. Suchorski, M. Piórkowska, H. Weiss, J. Catal. 2007, 247, 176-193. https://doi.org/10.1016/j.jcat.2007.01.013

37. B. Faure, G. Salazar-Alvarez, A. Ahniyaz, I. Villaluenga, G. Berriozabal, Y. R. De Miguel, L. Bergström, Sci. Technol. Adv. Mater. 2013, 14, 023001. https://doi.org/10.1088/1468-6996/14/2/023001

38. A. A. Keller, H. Wang, D. Zhou, H. S. Lenihan, G. Cherr, B. J. Cardinale, R. Miller, Z. Ji, Environ. Sci. Technol. 2010, 44, 1962-1967. https://doi.org/10.1021/es902987d

39. S. Mallakpour, M. Madani, Prog. Org. Coat. 2015, 86, 194207. https://doi.org/10.1016/j.porgcoat.2015.05.023

40. G. A. Farzi, R. Tayebee, S. Naghibinasab, Int. J. Nano Dimens. 2015, 6, 67-75.

\section{Povzetek}

Nanodelce aluminijevega(III) oksida $\left(\mathrm{Al}_{2} \mathrm{O}_{3}\right)$ smo pripravili z metodo obarjanja pri reakciji med raztopino amonijaka in $\left[\left(\mathrm{NH}_{4}\right) \mathrm{Al}(\mathrm{SO} 4)_{2} \cdot 12 \mathrm{H}_{2} \mathrm{O}\right]$ ter nadaljnjo kalcinacijo sedimenta pri $1200{ }^{\circ} \mathrm{C}$. Površino nanodelcev smo modificirali $\mathrm{z}$ oleinsko kislino (OA) in trimetoksivinilsilanom (TMVS) v o-ksilenu pri $50{ }^{\circ} \mathrm{C}$. Nanodelce $\mathrm{Al}_{2} \mathrm{O}_{3}$ in modificirane nanodelce smo karakterizirali z naslednjimi metodami: rentgensko praškovno difrakcijo (XRD), infrardečo spektroskopijo (FT-IR), vrstično elektronsko mikroskopijo (SEM), energijsko disperzivno rentgensko spektroskopijo (EDX) in termogravimetrično analizo (TGA). S TGA smo določali množino na površino nanodelcev vezane OA (10.5\%) in TMVS (8.0\%). Disperzijo modificiranih nanodelcev smo raziskovali v metil metakrilatu (MMA), butilakrilatu (BuA) in stirenu (St) ter topilih kot so etanol, heksan in aceton. Najboljša disperzija nanodelcev modificiranih z OA je bila v n-heksanu, $\mathrm{v}$ primeru delcev modificiranih s TMVS pa v acetonu. Rezultati kažejo, da dobimo stabilno disperzijo nanodelcev modificiranih z OA v MMA in BuA (začetni odstotki nanodelcev: 5\% in 2,5\%). $\mathrm{V}$ primeru nanodelcev modificiranih $\mathrm{s}$ TMVS pa lahko pripravimo stabilno disperzijo v stirenu (začetni odstotek nanodelcev: $2,5 \%$ ) 